\title{
Efficacy of intraoperative epidural triamcinolone application in lumbar microdiscectomy: a matched-control study
}

\author{
Martin N. Stienen, MD, ${ }^{1}$ Holger Joswig, MD, ${ }^{2}$ Ivan Chau, MD, ${ }^{2}$ Marian C. Neidert, MD, ${ }^{1}$ \\ David Bellut, MD, ${ }^{1}$ Thomas Wälchli, MD, PhD, ${ }^{1,3}$ Karl Schaller, MD, ${ }^{3}$ and Oliver P. Gautschi, MD ${ }^{3}$ \\ 1Department of Neurosurgery, University Hospital Zürich; ${ }^{2}$ Department of Neurosurgery, Cantonal Hospital St. Gallen; and \\ ${ }^{3}$ Department of Neurosurgery and Faculty of Medicine, University Hospital Geneva, Switzerland
}

\begin{abstract}
OBJECTIVE The purpose of this study was to investigate whether the intraoperative application of an epidural steroid (ES) on the decompressed nerve root improves short- and midterm subjective and objective clinical outcomes after lumbar microdiscectomy.
\end{abstract}

METHODS This study was a retrospective analysis of a 2-center database including consecutive cases in which patients underwent lumbar microdiscectomy. All patients who received ES application (40 mg triamcinolone, ES group) were matched by age and sex to patients who had not received ES application (control group). Objective functional impairment (OFI) was determined using age- and sex-adjusted T-scores of the Timed Up and Go (TUG) test. Back and leg pain (visual analog scale), functional impairment (Oswestry Disability Index [ODI], Roland-Morris Disability Index [RMDI], and health-related quality of life (hrQoL; 12-Item Short Form Health Survey [SF-12] physical component summary [PSC] score and EuroQol [EQ-5D index]) were measured at baseline, on postoperative day 3, and at postoperative week 6.

RESULTS Fifty-three patients who received ES application were matched with 101 controls. There were no baseline demographic or disease-specific differences between the study groups, and preoperative pain, functional impairment, and hrQoL were similar. On postoperative day 3, the ES group had less disability on the RMDI (mean $7.4 \mathrm{vs} \mathrm{10.3,p=}$ 0.003 ) and higher hrQoL as determined by the SF-12 PCS (36.5 vs 32.7, $p=0.004)$. At week 6 , the ES group had less disability on the RMDI ( 3.6 vs $5.7, p=0.050)$ and on the ODI by trend (17.0 vs $24.4, p=0.056)$; better hrQoL, determined by the SF-12 PCS (44.3 vs 39.9, $p=0.018$ ); and lower OFI (TUG test T-score 100.5 vs 110.2, $p=0.005$ ). The week 6 responder status based on the minimum clinically important difference (MCID) was similar in the ES and control groups for each metric. The rates and severity of complications were similar, with a $3.8 \%$ and $4.0 \%$ reoperation rate in the ES group and control group, respectively $(p=0.272)$. There was a tendency for shorter hospitalization in the ES group $(5.0$ vs 5.8 days, $p=0.066$ ).

CONCLUSIONS Intraoperative ES application on the decompressed nerve root is an effective adjunct treatment that may lower subjective and objective functional impairment and increase hrQoL in the short and intermediate term after lumbar microdiscectomy. However, group differences were lower than the commonly accepted MCIDs for each metric, indicating that the effect size of the benefit is limited.

- CLASSIFICATION OF EVIDENCE Type of question: therapeutic; study design: retrospective cohort trial; evidence: Class II. https://thejns.org/doi/abs/10.3171/2017.6.SPINE161372

KEY WORDS epidural steroid application; triamcinolone; lumbar disc surgery; outcome; complications; responder status; minimum clinically important difference; objective functional impairment

ABBREVIATIONS ASA = American Society of Anesthesiologists; $\mathrm{BMI}=$ body mass index; $\mathrm{CCl}=$ Charlson Comorbidity Index; $\mathrm{ES}=$ epidural steroid; hrQoL = health-related quality of life; LBP = low-back pain; LDH = lumbar disc herniation; $M C I D=$ minimum clinically important difference; ODI = Oswestry Disability Index; OFI = objective functional impairment; PCS = physical component summary; RMDI = Roland-Morris Disability Index; RR = risk ratio; SF-12 = 12-Item Short Form Health Survey; TUG = Timed Up and Go; VAS = visual analog scale.

SUBMITTED November 24, 2016. ACCEPTED June 14, 2017.

INCLUDE WHEN CITING Published online December 15, 2017; DOI: 10.3171/2017.6.SPINE161372. 


\section{- CLASSIFICATION OF EVIDENCE}

Type of Question Therapeutic

\section{Study Design Retrospective Cohort Trial}

\section{Evidence Class II}

Stienen and his associates have made an important contribution to the neurosurgical literature with the publication of this retrospective cohort trial using registry data from 2 Swiss hospitals. The authors examine whether the intraoperative administration of epidural triamcinolone following single-level lumbar microdiscectomy improves objective functional impairment (OFI) as measured by the Timed Up and Go test (their primary outcome), back and leg pain, disability, and quality of life, without increasing the complication rate. Although this study has been scrupulously executed, there are some potentially important preoperative differences between the treatment groups with respect to smoking, work status, degree of employment, ASA score (American Society of Anesthesiologists physical status classification), and the presence of motor deficits. None of these differences achieves statistical significance, but many may be clinically important, and the presence of multiple imbalances raises the concern that additional unmeasured but prognostically important differences might be present. In addition, the authors do not disclose whether their primary end point was determined by masked assessors. Although the Timed Up and Go test is a relatively objective end point, observer expectation bias remains possible in the absence of masked outcome assessment. Finally, the authors matched (by age and sex) patients who received and did not receive epidural steroid (ES) application, excluding $35(18.5 \%)$ of 189 potentially eligible patients from their trial. This process introduces an opportunity for selection bias and decreases the generalizability of the study results. Most importantly, although the authors demonstrated statistically significant differences in outcome between the ES and control treatment groups, none of the prespecified outcome measures differed by more than the minimum clinically important difference established for each of those measures. Integrating statistical and clinical significance, and factoring in the additional possibility that ES application could be associated with more complications than no ES application (OR 1.94, 95\% Cl $0.26-14.18, p=0.51$ ), the correct (and important) conclusion to draw from the current study is that epidural triamcinolone application may improve 6-week OFI, but it may be associated with an increased risk of infectious complications, so additional adequately powered and well-designed trials are essential before adopting this intervention into routine practice. Stienen and colleagues provide essential information about the potential effect size of this intervention and about what outcome measures should be used.

$$
\begin{array}{r}
\text { — Michael Glantz, MD } \\
\text { Hershey Medical Center } \\
\text { Hershey, Pennsylvania }
\end{array}
$$

$\mathrm{L}$ OW-BACK pain (LBP) and irradiating leg pain secondary to lumbar disc herniation (LDH) are generally thought to result from both mechanical pressure on the nerve roots and inflammatory response. ${ }^{35,46}$ While surgical removal of the herniated nucleus pulposus is effective in alleviating local pressure, the inflammatory mediators remain for days to weeks after the procedure. ${ }^{9}$ As a result of this, poorly controlled postoperative pain delays mobilization and the start of physiotherapy, thereby prolonging hospitalization and diminishing hope for recovery. ${ }^{43}$

Epidural steroid (ES) application during lumbar discectomy was first reported by Jones and Barnett in $1955 .^{28}$ They instilled $25-50 \mathrm{mg}$ of hydrocortisone in 50 patients and compared their outcomes with the outcomes of 50 patients who did not receive this treatment. The patients in the ES group showed a $40 \%$ reduction in use of opiate drugs and could be mobilized earlier. These promising results stimulated further investigation. With the ongoing development and validation of reliable generic and disease-specific measures of pain, functional impairment, and health-related quality of life (hrQoL), the effect of ES application during lumbar spine surgery has been reinvestigated..$^{3,25-27,32,34,37,43,44,46}$ In a recent systematic review, evidence suggested that intraoperative ES application is effective in reducing pain in the early period up to 2 weeks postoperatively, whereas the effectiveness in the intermediate (2 weeks to 2 months) and longer term (> 2 months) was rather weak. ${ }^{26}$ In these studies, subjective measures of disability were used, as standardized objective measures of function have been introduced only recently. ${ }^{15,16}$ In addition, the heterogeneous study designs make it difficult to derive firm conclusions concerning the effectiveness of intraoperative ES application. ${ }^{26}$ In view of this controversial debate, ${ }^{5,26}$ more studies using validated subjective and objective outcome measures are warranted.

Therefore, the present study aimed to investigate whether the direct application of ES on the decompressed nerve root during lumbar microdiscectomy improves objective functional impairment (OFI) and subjective clinical outcome.

\section{Methods}

A retrospective review of a prospective, IRB-approved 2-center database from 2 tertiary Swiss teaching hospitals was performed. Consecutive patients undergoing microdiscectomy for unilateral LDH between September 2013 and December 2015 were included.

\section{Null Hypothesis and Calculation of Sample Size}

The primary null hypothesis was that patients receiving ES application during lumbar discectomy (ES group) have similar OFI as patients without ES (control group). A secondary null hypothesis was formulated concerning equality of subjective pain, functional impairment, and hrQoL outcome. As no prior data concerning OFI are available, sample size calculations were based on the Oswestry Disability Index (ODI). Aljabi et al. ${ }^{3}$ reported 1-month ODI values of 34.1 and 42.6 for ES and control groups, respec- 
tively. Given a standard deviation of 10 , a sample size of 40 patients (20 patients in each arm) was required to demonstrate a statistically significant difference with a power of $80 \%$ and alpha set at 0.05 .

\section{Data Collection}

The database comprised general patient data (age, sex, body mass index [BMI], smoking, and working status), comorbidity and anesthesiology risk (Charlson Comorbidity Index $[\mathrm{CCI}]^{6}$ and American Society of Anesthesiologists [ASA] physical status classification ${ }^{29}$ ), and radiological markers of degeneration (Modic ${ }^{38}$ and Pfirrmann ${ }^{42}$ ).

OFI was determined using the Timed Up and Go (TUG) test with results standardized for age and sex. ${ }^{15,19,50}$ The TUG is a timed test that assesses some of the most basic but important functions of patients with lumbar degenerative disc disease, such as standing up, walking (as fast as possible), turning around, walking again, and sitting back down. For the TUG measurements, we used a specifically designed "TUG app" that is available for free download from the Apple and Google app stores. Preoperative LBP and irradiating leg pain were rated on a visual analog scale (VAS) from 0 to 10. Subjective functional impairment was measured by the Roland-Morris Disability Index (RMDI; from 0 [no disability] to 24 [severe disability]) and the ODI (from 0\% [no disability] to $100 \%$ [severe disability]). ${ }^{13,45}$ The hrQoL measures comprised the generic metrics 12-Item Short Form Health Survey (SF-12; physical component summary [PCS] score standardized to a mean of 50) and EQ-5D (EuroQoL Group; from -0.074 [worst hrQoL] to 1.00 [best hrQoL], using European norms). ${ }^{12}$

Outcome measurements using all metrics were obtained at baseline, as well as on postoperative day 3 and at week 6. Complications up to 30 days after surgery were classified according to Landriel Ibanez et al. ${ }^{30}$ Additionally, length of hospitalization was recorded.

\section{Surgical Intervention}

All patients underwent surgery in a knee-chest position under general anesthesia and received a single 2-g dose of intravenously administered cefazoline (Kefzol, Teva Pharma AG) preoperatively as antibiotic prophylaxis. After fluoroscopic confirmation of the correct level, patients were prepared and draped in the usual sterile fashion. A midline skin incision of $2.5-4 \mathrm{~cm}$ was made for singlelevel surgery. Scissors or monopolar cautery were used for fascia opening. The paravertebral musculature was scraped from the laminae using a Cobb elevator. Following a superior laminotomy, performed with a high-speed drill under microscopic view, the ligamentum flavum was partially resected, and the interlaminar window was extended laterally and inferiorly using Kerrison punches. Sequestrectomy was followed by partial microdiscectomy if considered necessary. Following copious irrigation and hemostasis, $40 \mathrm{mg}$ of triamcinolone (Kenacort, BristolMyers Squibb) was applied to the epidural space of the decompressed nerve root at the discretion of the surgeon. Patients were not aware of whether the steroid medication was applied. Drains were only inserted in the event of unsatisfactory hemostasis. The wound was closed in the usual fashion using subcutaneous sutures.

\section{Study Groups}

All patients who had received ES application (ES group) were matched for age and sex in a 1:2 fashion with controls who had not received ES application.

\section{Statistical Considerations}

The independent variables were OFI (TUG test), pain (VAS back and leg pain), subjective functional impairment (RMDI and ODI), and hrQoL measures (SF-12 PCS and EQ-5D). Categorical variables (presented as frequency and percentage) were tested for imbalance using Pearson chi-square tests. Nominal variables (presented as mean and SD) were compared using Student t-tests. The responder status to surgical treatment was defined using previously published minimum clinically important difference (MCID) values for OFI of 3.4 seconds, ${ }^{21}$ ODI of 12.8, RMDI of 5.0, SF-12 PCS of 4.9, and EQ-5D of $0.359 .^{7,48,51}$ The effect size of the relationship between ES application and the week 6 responder status was estimated using logistic regression analysis. No stepwise or other automated variable selections were used because of their well-known limitations. ${ }^{39}$

The software used for statistical analysis was Stata v14 (StataCorp LP); $\mathrm{p} \leq 0.05$ was considered statistically significant.

\section{Ethical Considerations}

The study was in accordance with the Code of Ethics of the World Medical Association (Declaration of Helsinki) and was approved by the local institutional review boards (University Hospital Geneva and Cantonal Hospital St. Gallen). All patients gave written informed consent.

\section{Results}

Of 377 patients in the database, 189 with LDH undergoing microdiscectomy without surgical fusion were found to be eligible for study inclusion. Of these, 53 patients had received ES application as described above (ES group). They were matched in a 1:2 ratio for the variables age and sex with 101 controls who underwent a similar operation without ES application. The combined cohort had a mean age of 46.9 years (SD 11.6), and $63.6 \%$ of the patients were male. There were no significant baseline demographic (Table 1) or disease-specific differences (Table 2) between the study groups. Table 3 summarizes the similar pain levels, subjective and objective impairment, and hrQoL before surgery in patients from the ES and control groups.

Figure 1 depicts longitudinal measures of subjective and objective functional impairment and hrQoL. At day 3, there was no significant difference between the ES group (T-score 127.4, 43.6) and the control group (T-score 129.0, 38.2) in terms of OFI. On the subjective metrics, the ES group had less disability on the RMDI (7.4 vs $10.3, \mathrm{p}=$ 0.003 ) and higher hrQoL on the SF-12 PCS (36.5 vs. 32.7, $\mathrm{p}=0.004)$. There was a tendency for less disability on the ODI for the ES group (30.9 vs. 36.5, p = 0.095). At week 
TABLE 1. Comparison of basic characteristics of patients in the ES and control groups

\begin{tabular}{|c|c|c|c|}
\hline Variable & $\begin{array}{l}\text { ES Group } \\
(n=53)\end{array}$ & $\begin{array}{l}\text { Controls } \\
(n=101)\end{array}$ & $\begin{array}{c}p \\
\text { Value }\end{array}$ \\
\hline Mean age in yrs (SD) & $45.8(13.6)$ & $47.5(10.4)$ & 0.376 \\
\hline Sex & & & 0.654 \\
\hline Male & $35(66.0)$ & $63(62.4)$ & \\
\hline Female & $18(34.0)$ & $38(37.6)$ & \\
\hline Mean BMI in $\mathrm{kg} / \mathrm{m}^{2}$ (SD) & $26.2(4.4)$ & $27.5(4.5)$ & 0.103 \\
\hline Smoking & & & 0.225 \\
\hline Yes & $22(41.5)$ & $32(31.7)$ & \\
\hline No & $31(58.5)$ & $69(68.3)$ & \\
\hline Work status & & & 0.060 \\
\hline Full-/part-time & $32(60.4)$ & $79(78.2)$ & \\
\hline Not working & $13(24.5)$ & $16(15.8)$ & \\
\hline Disabled & $3(5.7)$ & $4(4.0)$ & \\
\hline Retired & $5(9.4)$ & $2(2.0)$ & \\
\hline $\begin{array}{l}\text { Mean degree of employ- } \\
\text { ment (SD)* }\end{array}$ & $68.1 \%(47.1 \%)$ & $78.9 \%(38.9 \%)$ & 0.153 \\
\hline Morphine use & & & 0.807 \\
\hline No & $40(75.5)$ & $78(77.2)$ & \\
\hline Yes & $13(24.5)$ & $23(22.8)$ & \\
\hline ASA & & & 0.245 \\
\hline $0-1$ & $14(26.4)$ & $36(35.6)$ & \\
\hline $2-3$ & $39(73.6)$ & $65(64.4)$ & \\
\hline $\mathrm{CCl}$ & & & 0.605 \\
\hline $0-1$ & $50(94.3)$ & $93(92.1)$ & \\
\hline$\geq 2$ & $3(5.7)$ & $8(7.9)$ & \\
\hline
\end{tabular}

Data are presented as number of patients (\%) unless otherwise indicated.

* In employed patients, percentage relative to full-time employment.

6, patients of the ES group scored significantly lower than those in the control group for OFI (T-score 100.5, 10.0 vs $110.2,12.8, \mathrm{p}=0.005)$. They had less disability on the RMDI (3.6 vs 5.7, $\mathrm{p}=0.050)$ and on the ODI by trend (17.0 vs $24.4, \mathrm{p}=0.056)$, and better hrQoL determined by the SF-12 PCS (44.3 vs 39.9, $\mathrm{p}=0.018)$.

The MCID-based week 6 responder status was similar in the ES and control groups on each metric (Table 4). With respect to OFI, patients in the ES group were 0.69 times as likely as patients in the control group to be week 6 treatment responders $(95 \% \mathrm{CI} 0.22-2.14, \mathrm{p}=0.518)$.

The rates and severity of complications were similar in the 2 groups (Table 5), with $3.8 \%$ and $4.0 \%$ rates of repeat surgery (complication type $2 b$ ) in the ES and control groups, respectively $(p=0.272)$. Patients in the ES group were 1.94 times as likely as those in the control group to experience a surgical-site infection (OR 1.94, 95\% CI $0.26-14.18, \mathrm{p}=0.513 ; 3.8 \%$ vs $2.0 \%)$. There was a tendency for shorter duration of hospitalization in the ES group (5.0 vs 5.8 days, $\mathrm{p}=0.066$ ).

\section{Discussion}

In patients with LDH, early biopsy and autopsy findings of compressed and irritated, edematous posterior
TABLE 2. Comparison of preoperative disease-specific data in the ES and control groups

\begin{tabular}{cccc}
\hline \multicolumn{1}{c}{ Variable } & ES Group $(n=53)$ & Controls $(n=101)$ & $p$ Value \\
\hline Levels & & 0.688 \\
\hline 1 level & $52(98.1)$ & $98(97.0)$ & \\
\hline$\geq 2$ levels & $1(1.9)$ & $3(3.0)$ & \\
\hline Segment & & & 0.730 \\
\hline L2-3 & $-(0.0)$ & $1(1.0)$ & \\
\hline L3-4 & $7(13.2)$ & $11(10.9)$ & \\
\hline L4-5 & $20(37.7)$ & $45(44.6)$ & \\
\hline L5-S1 & $26(49.1)$ & $44(43.6)$ & \\
\hline Modic changes & & & \\
\hline No & $20(41.7)$ & $44(46.3)$ & \\
\hline Yes & $28(58.3)$ & $51(53.7)$ & \\
\hline Pfirrmann degree* & & & \\
\hline Low (0-3) & $24(50.0)$ & $43(45.3)$ & \\
\hline High (4-5) & $24(50.0)$ & $52(54.7)$ & \\
\hline Motor deficit & & & \\
\hline No & $39(73.6)$ & $66(65.4)$ & \\
\hline Yes & $14(26.4)$ & $35(34.7)$ & \\
\hline
\end{tabular}

Data are presented as number of patients (\%).

* Available in 143 (92.9\%) of 154 patients with preoperative MRI data.

nerve roots revealed inflammatory changes, ${ }^{8}$ which laid out the rationale for adding ES during lumbar disc surgery. Steroids are potent suppressors of inflammatory mediators, such as prostaglandins, leukotrienes, bradykinins, and histamines. ${ }^{2}$ In line with this pathophysiological concept, ES application has been shown to be associated with reduced pain due to reduction of nerve root edema and inflammation. ${ }^{22,35}$ The majority of previous reports were based on retrospective data and compared length of hospitalization, day of first mobilization, and use of mild/ strong pain medication, among other proxies of pain and disability. 1,8,14,28,31,36,37,40,44 Despite a paucity of prospective studies reporting a benefit and considerable variability in outcome, about half of North American neurosurgeons

TABLE 3. Subjective measures of pain, functional disability, and hrQoL in patients scheduled for lumbar microdiscectomy with or without ES application

\begin{tabular}{lccc}
\hline \multicolumn{1}{c}{ Measure } & ES $(n=53)$ & No ES $(n=101)$ & $p$ Value \\
\hline VAS, back pain & $3.7(2.8)$ & $3.5(2.6)$ & 0.624 \\
\hline VAS, leg pain & $5.7(2.5)$ & $5.0(2.6)$ & 0.119 \\
\hline RMDI & $12.4(5.3)$ & $12.8(4.8)$ & 0.618 \\
\hline ODI & $50.2(19.4)$ & $53.7(17.6)$ & 0.271 \\
\hline EQ-5D index & $0.435(0.218)$ & $0.501(0.213)$ & 0.080 \\
\hline SF-12 PCS & $30.8(7.9)$ & $29.9(7.3)$ & 0.491 \\
\hline SF-12 MCS & $39.7(9.3)$ & $41.6(12.2)$ & 0.316 \\
\hline OFI T-score & $132.3(35.6)$ & $143.7(55.7)$ & 0.182 \\
\hline
\end{tabular}

MCS = mental component score.

Data are presented as mean (SD). 

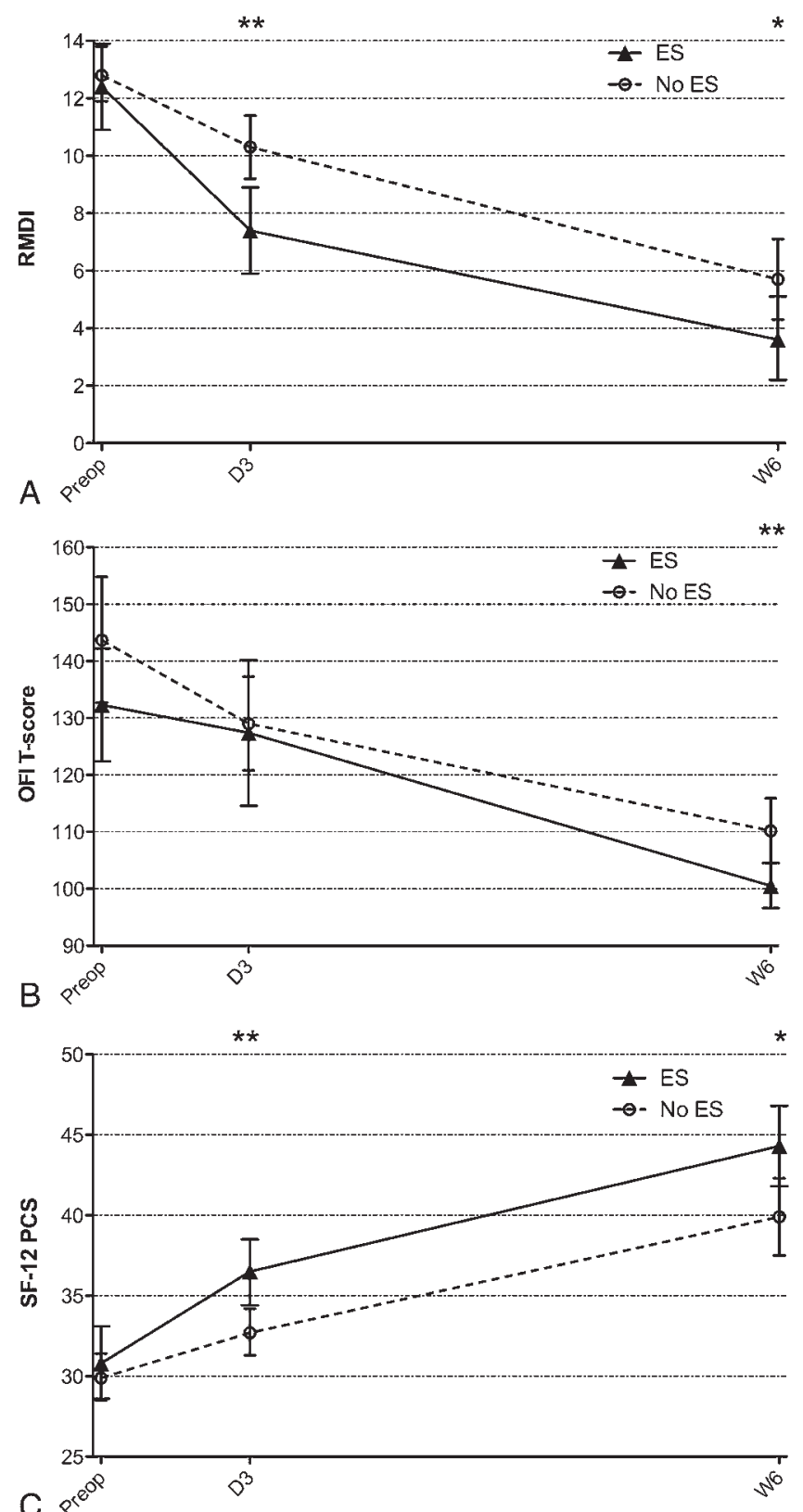

FIG. 1. Longitudinal measures of subjective (A) and objective (B) functional impairment and $\mathrm{hrQLL}(\mathrm{C})$ in patients who underwent lumbar microdiscectomy with or without ES. The x-axes represent the 3 time points at which measurements were obtained: preoperatively (Preop), postoperative day 3 (D3), and postoperative week 6 (W6). Data are presented as group means with $95 \%$ confidence intervals (error bars). The OFI T-scores are adjusted for age and sex. ${ }^{*} p \leq 0.05 ;{ }^{* *} p \leq 0.005$.

use ES application in lumbar disc surgery on a regular basis. ${ }^{5}$ Given that the other half do not use ES application, its efficacy is still a matter of controversy. ${ }^{26}$ Recent meta-analyses highlight the need for studies with validated outcome measures at fixed time intervals. ${ }^{26,43}$ The present data provide robust estimates of the treatment effect of ES application during lumbar microdiscectomy on a comprehensive panel of validated subjective and objective generic and disease-specific outcome measures of pain, functional impairment, and hrQoL. The data show a small but sta-
TABLE 4. Univariate analysis of the effect size describing the relationship of ES application to responder status 6 weeks after microdiscectomy

\begin{tabular}{lccc}
\hline \multirow{2}{*}{ Variable } & \multicolumn{3}{c}{ Univariate Analysis } \\
\cline { 2 - 4 } & OR & $95 \% \mathrm{Cl}$ & $\mathrm{p}$ Value \\
\hline VAS, back pain & 1.05 & $0.32-3.39$ & 0.940 \\
\hline VAS, leg pain & 2.88 & $0.71-11.6$ & 0.138 \\
\hline RMDI & 1.46 & $0.59-3.62$ & 0.416 \\
\hline ODI & 1.60 & $0.51-5.01$ & 0.419 \\
\hline EQ-5D index & 1.56 & $0.66-3.68$ & 0.312 \\
\hline SF-12 PCS & 2.55 & $0.85-7.69$ & 0.096 \\
\hline OFI & 0.69 & $0.22-2.14$ & 0.518 \\
\hline
\end{tabular}

tistically significant benefit for patients in the ES group, both at 3 days and at 6 weeks after surgery, with similar complication rates in the ES and control groups.

The credibility of the observations is substantiated by internal consistencies both within and between outcome measures, as well as by validity between actual observed and theoretically expected improvements conferred through the use of the tested intervention. Internal consistency is evident within the reduction of pain, objective and subjective functional impairment, and improvement in hrQoL. Each of these outcome measures demonstrated improved results in the ES group compared with the matched control group, commencing at day 3 and persisting to week 6 . Validity (expected compared with observed) can be appreciated at 2 levels. Surgery leads to marked improvement on all analyzed metrics, independent of the study group. This improvement was graduated, being measurable at day 3 and more substantial at week 6 follow-up. It corresponds to the typical postoperative course after lumbar microdiscectomy, lending credibility to the observed group differences. The second level of validity pertains to patient performance by group. Based on the previous literature, it could be expected that if a group difference was observed, this difference would be in favor of the intervention and measurable on several of the applied outcome metrics.

\section{Objective Functional Outcome}

Our results are in line with those of Jones and Barnett, who demonstrated a $40 \%$ reduction in the need for postoperative opiate injections in a cohort of 50 lumbar discectomy patients receiving $25-50 \mathrm{mg}$ of hydrocortisone epidurally as early as 1955 . The authors also reported on

TABLE 5. Rates and severity of complications within $\mathbf{3 0}$ days of surgery

\begin{tabular}{cccc}
\hline Complication* $^{*}$ & ES Group $(n=53)$ & Controls $(n=101)$ & p Value \\
\cline { 1 - 3 } None & $51(96.2)$ & $91(90.1)$ & \\
\cline { 1 - 3 } Grade 1a & $-(0.0)$ & $6(5.9)$ & \multirow{2}{*}{0.272} \\
\cline { 1 - 3 } Grade 2b & $2(3.8)$ & $4(4.0)$ & \\
\hline
\end{tabular}

Data are presented as number of patients (\%).

* According to the classification of Landriel Ibañez et al. ${ }^{30}$ 
ambulation on postoperative day 3 , which was resumed in $90 \%$ of the patients who received ES treatment, compared with only $40 \%$ of the control group. ${ }^{28}$ More than 60 years later, patients are generally mobilized much earlier as a result of the development of less invasive microscopic procedures. In addition, more sophisticated tools to objectively measure functional outcomes after lumbar disc surgery have been established. ${ }^{16}$ In the present study, the TUG test was used to measure OFI. ${ }^{50}$ This test involves some of the functions most relevant to maintaining good quality of life for patients with lumbar degenerative disc disease, namely standing up, walking, changing direction, and sitting down again. ${ }^{15,16}$ Results are presented as T-scores, standardized for age and sex using normal population data. ${ }^{19}$ Our results clearly show that OFI at week 6 was lower in the ES group than in the control group. For the first time, these findings demonstrate that lower pain and subjective perception of disability and higher hrQoL due to ES use also translate into objectively measurable lower functional impairment. It is important to note that OFI was similar in the early postoperative period (day 3); this is explained by acute wound pain (LBP), which was shown to influence OFI most at day 3. ${ }^{18}$ This acute pain, originating from muscular damage and osteo-ligamentous manipulation, is less influenced by ES application.

\section{Subjective Patient-Reported Outcomes}

With respect to subjective outcomes, there are 2 reviews addressing the efficacy of ES application for pain reduction in patients undergoing lumbar discectomy. ${ }^{26,43}$ The more recent review reported a significant pain reduction with ES application in $9(82 \%)$ of 11 trials in the early postoperative period (0-2 weeks), in $4(57 \%)$ of 7 trials in the intermediate period ( 2 weeks-2 months), and in $2(25 \%)$ of 8 trials in the late period ( $>2$ months). Thus, the evidence in support of intraoperative ES application reducing early postoperative pain can be considered strong, while for the intermediate period, it can be considered weak, and for the late period, the evidence against benefit for ES application is relatively strong. ${ }^{26}$ On the VAS for LBP and irradiating leg pain, we did not observe significant differences at day 3 and week 6 (data not shown).

It is commonly accepted that the use of multidimensional disease-specific questionnaires to estimate functional outcome of spine surgery is superior to the use of pain-intensity measures alone. ${ }^{11}$ However, so far only a few studies exploring the effect of ES agents have integrated multidimensional outcome measures of function. Aljabi et al. randomly assigned patients with unilateral LDH to local application of either a sponge soaked in a steroid medication or a sponged soaked in normal saline solution at the end of the operative procedure. ${ }^{3}$ The authors demonstrated a statistically significant reduction of the ODI at 1 week (41.3 vs 54.2, $\mathrm{p}=0.014)$ and 1 month after surgery (34.1 vs 42.6, $\mathrm{p}=0.004$ ) in favor of the ES group. Also, by using the ODI, Shin et al. showed a small but statistically significant advantage for the ES group 1 week after percutaneous endoscopic lumbar discectomy (20.7 vs 27.0, $\mathrm{p}<0.01) .{ }^{46}$ As in our study (Table 4), the absolute differences between the study groups in the reports by Aljabi et al. and Shin et al. were below the 12.8-point MCID of the ODI. ${ }^{3,46}$ Finally, Jirarattanaphochai et al. used the ODI in a prospective randomized study including patients undergoing microdiscectomy, lumbar decompression, and surgical fusion. ${ }^{27}$ The authors found no significant group difference in the ODI at 1 or 3 months after surgery (group means were not reported). Similarly, Lundin et al. ${ }^{34}$ found no significant difference on the 12-item Disability Rating Index while evaluating physical function in patients randomized to perioperative steroid treatment (including ES application) or placebo (normal saline solution). No previous study used the RMDI to measure the functional outcome after intraoperative ES application; on this metric we found superior results in the ES group (Fig. 1A).

Concerning hrQoL, Hurlbert et al. first demonstrated in a prospective randomized approach that patients who received an analgesic epidural paste containing methylprednisolone and morphine had more favorable general health status at week 6 , as determined by the mean SF-36 score. ${ }^{25}$ In 2007, Jirarattanaphochai et al. showed that SF36 scores were consistently higher in the ES group than in the control group. However, this difference was significant only in the vitality and mental function subscales. ${ }^{27} \mathrm{We}$ used the SF-12 questionnaire to calculate the summary score for physical health (PCS). At day 3 and week 6 , the ES group scored higher on this metric (Fig. 1C), and the mean group difference was close to the MCID (Table 4). We are not aware of prior studies that used the EQ-5D, but although postoperative improvement was seen on this metric for both groups, the questionnaire performed poorly in differentiating between the ES and the control group.

\section{Safety of ES Application}

Concerns about the safety of ES application have been raised by authors of smaller series, in particular with respect to deep infections and epidural abscess formation. ${ }^{2,33}$ As early as the 1980 s, Delaney et al..$^{10}$ demonstrated in an experimental model that epidural triamcinolone did not result in significant histological changes and that histological findings were in fact comparable to those in controls. A recent systematic literature review analyzing the data of 1933 patients (742 of whom received ES application) revealed similar overall complication rates in patients with and without ES application (risk ratio [RR] 1.94, 95\% CI 0.72-5.26, $\mathrm{p}=0.19$; including infection, arachnoiditis, recurrent $\mathrm{LDH}$, durotomy, and cerebrospinal fluid leak). With respect to infectious complications, a nonsignificant trend toward more infections in patients receiving ES application was noted (RR 4.58, 95\% CI 0.75-27.95, $\mathrm{p}=0.10) .^{2}$ Our present findings are in line with those of Akinduro et al., ${ }^{2}$ as the rates and severity of postoperative complications were similar in both groups (Table 5) despite a nonsignificant trend toward more surgical-site infections in the ES group. There was no higher rate of wound healing problems (minor, not requiring revision surgery; Landriel Ibañez Grade 1) in the ES group (Table $5){ }^{30}$ The second concern pertains to impaired healing of the annulus fibrosus by steroid-induced inhibition of fibroplasia potentially resulting in more frequent recurrences. ${ }^{46}$ As only complications within 30 days of surgery were recorded in the present study, the matter of late complications, such as slow infections or recurrences, cannot be 
addressed. The findings of Rasmussen et al., who provided a 2-year follow-up of 99 patients in each group, with and without ES application, demonstrate similar rates of recurrent LDH surgeries (7\% vs 8\%, $\mathrm{p}>0.99$; in each, 2 patients for recurrence), which speaks against a strong negative effect of ES application. ${ }^{44}$

\section{Strengths and Limitations}

This study is a retrospective analysis of prospectively collected data from 2 centers in different language areas (German and French), which helps to generalize the findings to a broader population. No significant differences in potential confounders, such as age,${ }^{20}$ sex,${ }^{17}$ and BMI,${ }^{47}$ were present, which eliminates bias with respect to the primary and secondary outcomes. As the subjective perception of pain is influenced by physiological, sensory, affective, cognitive, sociocultural, and behavioral factors, this study included a validated objective measure of function. ${ }^{19}$ Simple but robust statistical approaches were chosen, referring not only to statistical significance, but also to the clinical relevance of the effect. A placebo effect is unlikely to be present in this study as patients were blinded with respect to the study intervention.

Because this was not a randomized study, selection bias does apply and the above-mentioned limitations of previous retrospective studies apply to the present work as well. Surgeons were more likely to use ES application in cases requiring more mechanical manipulation of the nerve root, which potentially leads to an underestimation of the treatment effect. The rationale for an MCID-based definition of treatment response is to assess whether patients notice a clinically meaningful improvement. ${ }^{21}$ This definition of treatment response, however, assumes stability of other variables that might factor into the outcome. It should be pointed out that the true positive effect of ES application on the clinical outcomes might be underestimated, as the use of postoperative (opioid) analgesics was not standardized and has been reported to be lower in patients who had received ES treatment. ${ }^{2}$ On the other hand, ES application was not used in patients with diabetes or in cases where epidural hemorrhage required insertion of a drain, and this could lead to an overestimation of the treatment effect. Only outcomes up to 6 weeks after surgery were considered, which could mask the long-term effects of epidural ES application. However, recent studies show that most improvement after noninstrumented microscopic spine surgery can be expected within the first 6 weeks. ${ }^{24,48}$ Also, long-term effects of ES application, such as a reduction of epidural scar formation, could not be confirmed. ${ }^{23}$ Previous studies almost unequivocally disproved longterm (i.e., $>6$ weeks postoperative) effectiveness of intraoperative ES application., ${ }^{9,25,26}$ Comparing return-to-work rates in patients with and without ES treatment would have been desirable, ${ }^{4,52}$ but these data were not available. Finally, with regard to the current literature, dosage and types of steroids varied considerably, as did surgical techniques and postoperative care, rendering comparison with our results difficult. ${ }^{26}$

\section{Implications for Clinical Practice}

Integrating the present findings and the available litera- ture on this subject, it appears that removing the sequester as the cause of the lumbar nerve root compression is by far the most important factor in achieving symptomatic relief. ${ }^{27,31}$ There is good evidence that ES application can significantly reduce the use of early postoperative opioid analgesic use, and potentially leads to lower incidences of oversedation, respiratory depression, constipation, ileus, and other adverse effects linked to opioids. ${ }^{2,49}$ The addition of ES likely reduces pain and functional impairment and increases patients' hrQoL after microdiscectomy for $\mathrm{LDH}$, at least in the first weeks following the procedure. The effect size of this adjunct was found to be below the MCID in all studies, including the present one. Thus, the effect might not translate into a clinically meaningful one. However, in view of the weaknesses of previous studies and the present one, as discussed above, the true benefit of ES application might in fact be underestimated. Studies consistently report better or similar outcomes for the group receiving ES, whereas no study so far has reported worse outcomes, although publication bias might be present. ${ }^{43} \mathrm{ES}$ might not come without risk, and as the use of ES after lumbar discectomy has been linked with higher infection rates by trend, ${ }^{2}$ we do not recommend its use in patients with diabetes or those who are immunocompromised. In the absence of robust data on this aspect, some authorsincluding us-recommend not using ES in cases of durotomy during surgery, as arachnoiditis and neurotoxic effects have been reported. ${ }^{2,41}$ Considering the reduced hospitalization time, the relatively low cost of the applied steroid may be ameliorated by reduced overall costs. Taking into consideration the probable benefit with the potential drawbacks in mind, we propose to include ES application in the preoperative informed consent.

\section{Conclusions}

Intraoperative epidural application of steroids on the decompressed nerve is an effective treatment adjunct to lower subjective and objective functional disability and increase hrQoL in the short- and midterm after lumbar microdiscectomy. However, observed differences were lower than the commonly accepted MCIDs of each outcome metric, indicating that the effect size of the benefit is limited. As some data suggest an increased rate of surgical-site infections, risks and benefits need to be carefully weighed and the intervention should at best be discussed with the patient when obtaining informed consent.

\section{Acknowledgments}

We thank Dr. Marco V. Corniola and Cornelia Lüthi (study nurse) for helping to collect the outcome data.

\section{References}

1. Abrishamkar S, Rafiei AR, Sabouri M, Moradi S, Tabesh $\mathrm{H}$, Rahmani P, et al: The effect of impregnated autogenous epidural adipose tissue with bupivacaine, methylprednisolone acetate or normal saline on postoperative radicular and low back pain in lumbar disc surgery under spinal anesthesia; a randomized clinical trial study. J Res Med Sci 16:621-626, 2011

2. Akinduro OO, Miller BA, Haussen DC, Pradilla G, Ahmad 
FU: Complications of intraoperative epidural steroid use in lumbar discectomy: a systematic review and meta-analysis. Neurosurg Focus 39(4):E12, 2015

3. Aljabi Y, El-Shawarby A, Cawley DT, Aherne T: Effect of epidural methylprednisolone on post-operative pain and length of hospital stay in patients undergoing lumbar microdiscectomy. Surgeon 13:245-249, 2015

4. Asher AL, Chotai S, Devin CJ, Archer-Swygert K, Parker SL, Bydon M, et al: Predictive model for return to work after elective surgery for lumbar degenerative disease: an analysis from National Neurosurgery Quality Outcomes Database Registry. Neurosurgery 63 (Suppl 1):160, 2016 (Abstract 148)

5. Cenic A, Kachur E: Lumbar discectomy: a national survey of neurosurgeons and literature review. Can J Neurol Sci 36:196-200, 2009

6. Charlson ME, Pompei P, Ales KL, MacKenzie CR: A new method of classifying prognostic comorbidity in longitudinal studies: development and validation. J Chronic Dis 40:373383, 1987

7. Copay AG, Glassman SD, Subach BR, Berven S, Schuler TC, Carreon LY: Minimum clinically important difference in lumbar spine surgery patients: a choice of methods using the Oswestry Disability Index, Medical Outcomes Study questionnaire Short Form 36, and pain scales. Spine J 8:968-974, 2008

8. Davis R, Emmons SE: Benefits of epidural methylprednisolone in a unilateral lumbar discectomy: a matched controlled study. J Spinal Disord 3:299-307, 1990

9. Debi R, Halperin N, Mirovsky Y: Local application of steroids following lumbar discectomy. J Spinal Disord Tech 15:273-276, 2002

10. Delaney TJ, Rowlingson JC, Carron H, Butler A: Epidural steroid effects on nerves and meninges. Anesth Analg 59:610-614, 1980

11. Deyo RA, Battie M, Beurskens AJ, Bombardier C, Croft P, Koes B, et al: Outcome measures for low back pain research. A proposal for standardized use. Spine (Phila Pa 1976) 23:2003-2013, 1998

12. EuroQol Group: EuroQol-a new facility for the measurement of health-related quality of life. Health Policy 16:199208, 1990

13. Fairbank JC, Couper J, Davies JB, O'Brien JP: The Oswestry low back pain disability questionnaire. Physiotherapy 66:271-273, 1980

14. Foulkes GD, Robinson JS Jr: Intraoperative dexamethasone irrigation in lumbar microdiskectomy. Clin Orthop Relat Res (261):224-228, 1990

15. Gautschi OP, Corniola MV, Joswig H, Smoll NR, Chau I, Jucker D, et al: The timed up and go test for lumbar degenerative disc disease. J Clin Neurosci 22:1943-1948, 2015

16. Gautschi OP, Corniola MV, Schaller K, Smoll NR, Stienen $\mathrm{MN}$ : The need for an objective outcome measurement in spine surgery-the timed-up-and-go test. Spine J 14:25212522, 2014

17. Gautschi OP, Corniola MV, Smoll NR, Joswig H, Schaller K, Hildebrandt G, et al: Sex differences in subjective and objective measures of pain, functional impairment, and healthrelated quality of life in patients with lumbar degenerative disc disease. Pain 157:1065-1071, 2016

18. Gautschi OP, Joswig H, Corniola MV, Smoll NR, Schaller K, Hildebrandt G, et al: Pre- and postoperative correlation of patient-reported outcome measures with standardized Timed Up and Go (TUG) test results in lumbar degenerative disc disease. Acta Neurochir (Wien) 158:1875-1881, 2016

19. Gautschi OP, Smoll NR, Corniola MV, Joswig H, Chau I, Hildebrandt G, et al: Validity and reliability of a measurement of objective functional impairment in lumbar degenerative disc disease: the Timed Up and Go (TUG) Test. Neurosurgery 79:270-278, 2016
20. Gautschi OP, Smoll NR, Joswig H, Corniola MV, Schaller K, Hildebrandt G, et al: Influence of age on pain intensity, functional impairment and health-related quality of life before and after surgery for lumbar degenerative disc disease. Clin Neurol Neurosurg 150:33-39, 2016

21. Gautschi OP, Stienen MN, Corniola MV, Joswig H, Schaller $\mathrm{K}$, Hildebrandt G, et al: Assessment of the minimum clinically important difference in the timed up and go test after surgery for lumbar degenerative disc disease. Neurosurgery 80:380-385, 2017

22. Green LN: Dexamethasone in the management of symptoms due to herniated lumbar disc. J Neurol Neurosurg Psychiatry 38:1211-1217, 1975

23. Häckel M, Masopust V, Bojar M, Ghaly Y, Horínek D: The epidural steroids in the prevention of epidural fibrosis: MRI and clinical findings. Neuroendocrinol Lett 30:51-55, 2009

24. Häkkinen A, Kautiainen H, Järvenpää S, Arkela-Kautiainen M, Ylinen J: Changes in the total Oswestry Index and its ten items in females and males pre- and post-surgery for lumbar disc herniation: a 1-year follow-up. Eur Spine J 16:347-352, 2007

25. Hurlbert RJ, Theodore N, Drabier JB, Magwood AM, Sonntag VK: A prospective randomized double-blind controlled trial to evaluate the efficacy of an analgesic epidural paste following lumbar decompressive surgery. J Neurosurg 90 (2 Suppl): 191-197, 1999

26. Jamjoom BA, Jamjoom AB: Efficacy of intraoperative epidural steroids in lumbar discectomy: a systematic review. BMC Musculoskelet Disord 15:146, 2014

27. Jirarattanaphochai K, Jung S, Thienthong S, Krisanaprakornkit W, Sumananont C: Peridural methylprednisolone and wound infiltration with bupivacaine for postoperative pain control after posterior lumbar spine surgery: a randomized double-blinded placebo-controlled trial. Spine (Phila Pa 1976) 32:609-617, 2007

28. Jones KG, Barnett HC: The use of hydrocortisone in spinal surgery. South Med J 48:617-623, 1955

29. Keats AS: The ASA classification of physical status-a recapitulation. Anesthesiology 49:233-236, 1978

30. Landriel Ibañez FA, Hem S, Ajler P, Vecchi E, Ciraolo C, Baccanelli M, et al: A new classification of complications in neurosurgery. World Neurosurg 75:709-715, 604-611, 2011

31. Lavyne MH, Bilsky MH: Epidural steroids, postoperative morbidity, and recovery in patients undergoing microsurgical lumbar discectomy. J Neurosurg 77:90-95, 1992

32. Lotfinia I, Khallaghi E, Meshkini A, Shakeri M, Shima M, Safaeian A: Interaoperative use of epidural methylprednisolone or bupivacaine for postsurgical lumbar discectomy pain relief: a randomized, placebo-controlled trial. Ann Saudi Med 27:279-283, 2007

33. Lowell TD, Errico TJ, Eskenazi MS: Use of epidural steroids after discectomy may predispose to infection. Spine (Phila Pa 1976) 25:516-519, 2000

34. Lundin A, Magnuson A, Axelsson K, Kogler H, Samuelsson L: The effect of perioperative corticosteroids on the outcome of microscopic lumbar disc surgery. Eur Spine J 12:625630,2003

35. Marshall LL, Trethewie ER: Chemical irritation of nerveroot in disc prolapse. Lancet 2:320, 1973

36. McNeill TW, Andersson GB, Schell B, Sinkora G, Nelson J, Lavender SA: Epidural administration of methylprednisolone and morphine for pain after a spinal operation. A randomized, prospective, comparative study. J Bone Joint Surg Am 77:1814-1818, 1995

37. Mirzai H, Tekin I, Alincak H: Perioperative use of corticosteroid and bupivacaine combination in lumbar disc surgery: a randomized controlled trial. Spine (Phila Pa 1976) 27:343346, 2002

38. Modic MT, Steinberg PM, Ross JS, Masaryk TJ, Carter JR: 
Degenerative disk disease: assessment of changes in vertebral body marrow with MR imaging. Radiology 166:193-199, 1988

39. Mundry R, Nunn CL: Stepwise model fitting and statistical inference: turning noise into signal pollution. Am Nat 173:119-123, 2009

40. Naylor A, Flowers MW, Bramley JE: The value of dexamethasone in the postoperative treatment of lumbar disc prolapse. Orthop Clin North Am 8:3-8, 1977

41. Nelson DA, Landau WM: Intraspinal steroids: history, efficacy, accidentality, and controversy with review of United States Food and Drug Administration reports. J Neurol Neurosurg Psychiatry 70:433-443, 2001

42. Pfirrmann CW, Metzdorf A, Zanetti M, Hodler J, Boos N: Magnetic resonance classification of lumbar intervertebral disc degeneration. Spine (Phila Pa 1976) 26:1873-1878, 2001

43. Ranguis SC, Li D, Webster AC: Perioperative epidural steroids for lumbar spine surgery in degenerative spinal disease. A review. J Neurosurg Spine 13:745-757, 2010

44. Rasmussen S, Krum-Møller DS, Lauridsen LR, Jensen SE, Mandøe H, Gerlif C, et al: Epidural steroid following discectomy for herniated lumbar disc reduces neurological impairment and enhances recovery: a randomized study with twoyear follow-up. Spine (Phila Pa 1976) 33:2028-2033, 2008

45. Roland M, Fairbank J: The Roland-Morris Disability Questionnaire and the Oswestry Disability Questionnaire. Spine (Phila Pa 1976) 25:3115-3124, 2000

46. Shin SH, Hwang BW, Keum HJ, Lee SJ, Park SJ, Lee SH: Epidural steroids after a percutaneous endoscopic lumbar discectomy. Spine (Phila Pa 1976) 40:E859-E865, 2015

47. Stienen MN, Joswig H, Smoll NR, Corniola MV, Schaller K, Hildebrandt G, et al: Influence of body mass index on subjective and objective measures of pain, functional impairment and health-related quality of life in lumbar degenerative disc disease. World Neurosurg 96:570-577, 577.e1, 2016

48. Stienen MN, Joswig H, Smoll NR, Corniola MV, Schaller K, Hildebrandt G, et al: Short- and long-term outcome of microscopic lumbar spine surgery in patients with predominant back or predominant leg pain. World Neurosurg 93:458465, 465.e1, 2016
49. Stienen MN, Smoll NR, Hildebrandt G, Schaller K, Tessitore E, Gautschi OP: Constipation after thoraco-lumbar fusion surgery. Clin Neurol Neurosurg 126:137-142, 2014

50. Stienen MN, Smoll NR, Joswig H, Corniola MV, Schaller $\mathrm{K}$, Hildebrandt G, et al: Validation of the baseline severity stratification of objective functional impairment in lumbar degenerative disc disease. J Neurosurg Spine 26:598-604, 2017

51. Stratford PW, Binkley JM, Riddle DL, Guyatt GH: Sensitivity to change of the Roland-Morris Back Pain Questionnaire: part 1. Phys Ther 78:1186-1196, 1998

52. Than KD, Curran JN, Resnick DK, Shaffrey CI, Ghogawala $\mathrm{Z}$, Mummaneni PV: How to predict return to work after lumbar discectomy: answers from the NeuroPoint-SD registry. J Neurosurg Spine 25:181-186, 2016

\section{Disclosures}

The authors report no conflict of interest concerning the materials or methods used in this study or the findings specified in this paper.

\section{Author Contributions}

Conception and design: Stienen, Gautschi. Acquisition of data: Stienen, Joswig, Chau, Gautschi. Analysis and interpretation of data: Stienen, Joswig, Neidert, Bellut, Wälchli, Gautschi. Drafting the article: Stienen. Critically revising the article: Joswig, Chau, Neidert, Bellut, Wälchli, Schaller, Gautschi. Reviewed submitted version of manuscript: Stienen. Approved the final version of the manuscript on behalf of all authors: Stienen. Statistical analysis: Stienen. Administrative/technical/material support: Schaller, Gautschi. Study supervision: Bellut, Schaller, Gautschi.

\section{Correspondence}

Martin N. Stienen, Department of Neurosurgery, University Hospital Zürich, Frauenklinikstrasse 10, Zürich 8091, Switzerland. email: mnstienen@gmail.com. 